\title{
Retraction Note to: Machine learning-based prediction of urban soil environment and corpus translation teaching
}

\author{
Xueyuan $\mathrm{Xu}^{1}$
}

Published online: 11 November 2021

(c) Saudi Society for Geosciences 2021

Retraction Note to: Arabian Journal of Geosciences (2021) 14: 1031 https://doi.org/10.1007/s12517-021-07338-2

The Editor-in-Chief and the Publisher have retracted this article because the content of this article is nonsensical. The peer review process was not carried out in accordance with the Publisher's peer review policy. The author has not responded to correspondence regarding this retraction.

The original article can be found online at https://doi.org/10.1007/ s12517-021-07338-2.

Xueyuan $\mathrm{Xu}$

xuxueyuan2020@126.com

1 Foreign Language School, Chengdu University

of Traditional Chinese Medicine, Chengdu 610000, Sichuan,

China 